\title{
The kinetics of surface area reduction during isothermal sintering of hydroxyapatite adsorbent
}

\author{
S. Bailliez, A. Nzihou* \\ Ecoles des Mines d'Albi-Carmaux, Centre Energétique et Environnement, Laboratoire de Génie des Procédés des Solides Divisés, \\ UMR CNRS 2392, Campus Jarlard, Route de Teillet, 81013 Albi Cedex 09, France
}

\begin{abstract}
The behaviour of non-stoichiometric hydroxyapatite (HA) during the calcination in a solid bed was investigated. The structural properties are described in terms of the specific surface area. Calcination led to a significant decrease of the specific surface area by particle coalescence and densification. Hydroxyapatite begins to shrink near $780^{\circ} \mathrm{C}$ and reaches $97 \%$ theoretical density at $1100{ }^{\circ} \mathrm{C}$. The specific surface area and density variations are caused both by sintering and chemical reaction. Sintering data from these solids were correlated as a function of time and temperature. The rate of sintering is assumed to obey an Arrhenius equation. These results are compared with a number of literature models describing the mechanism of sintering kinetics using the specific surface area, and a good agreement is observed. The kinetic equation used is based on sintering driven by the curvature gradient in the interparticle neck region associated with initial stage sintering. Then, the decline in specific surface area is accurately described by the empirical equation of the form $\mathrm{d} S / \mathrm{d} t=-B(T) k^{b}$. The changing value of $b$, also known as the "order" of the reaction, suggests that the diffusion mechanism for loss of surface area may be a function of the temperature.
\end{abstract}

Keywords: Hydroxyapatite; Calcination; Sintering; Kinetics; Diffusion

\section{Introduction}

Immobilisation is a promising technology for cleaning up contaminated wastes and soils. Phosphate minerals would appear to have the potential to immobilise heavy metal contaminants in wastes and soils due to the low solubility of many orthophosphates of divalent metal ions [1-6]. Hydroxyapatite (HA) which is an insoluble calcium phosphate mineral of composition $\mathrm{Ca}_{10}\left(\mathrm{PO}_{4}\right)_{6}(\mathrm{OH})_{2}$ has been used as a cation exchanger and adsorbent in wastewater treatment and has a very high capacity for removing divalent heavy metal ions from water and liquid waste [7-11]. The exact mechanisms providing the retention of heavy metals by HA are not clear. Three types of reactions may control the retention of heavy metals by the HA matrix: surface adsorption, cation exchange (substitution) or precipitation.

Some of the mechanisms described above are reversible depending on the $\mathrm{pH}$ conditions, and the trapped metal can be leached and cause pollution when the residues are landfilled or reused. The insolubilisation of hydroxyapatite

\footnotetext{
* Corresponding author. Tel.: +33-5-63-49-32-22 fax: +33-5-63-49-30-99.

E-mail address: nzihou@enstimac.fr (A. Nzihou).
}

absorbents containing heavy metal is obtained by calcination. This leads to significant textural changes, mainly concerning specific surface area, porosity, particle size and density. Other phenomena observed during the calcination are the structural change due to crystallisation of the matrices and the formation of the neo-adsorbent when heavy metals are incorporated [12].

Before reacting a heavy metal contaminant the waste with a hydroxyapatite matrix, it seems useful to first understand the mechanisms that occur when only the pure hydroxyapatite is calcinated.

The results presented in this paper deal with the calcination of two hydroxyapatites: the first contains tricalcium phosphates and the second contains some carbonates. This first step is necessary to compare the behaviour of hydroxyapatite matrix doped and free of metal ions during the sintering process, and then understand the mechanism of the stabilisation of the heavy metal in a hydroxyapatite matrix. The parameters monitored are the crystallisation process, the specific surface area, the density and the weight variations.

The structural changes due to the combined effects of sintering and the reaction of hydroxyapatite formation are used to express the kinetics of the sintering of hydroxyapatite. This paper presents a review of the literature on sintering, 


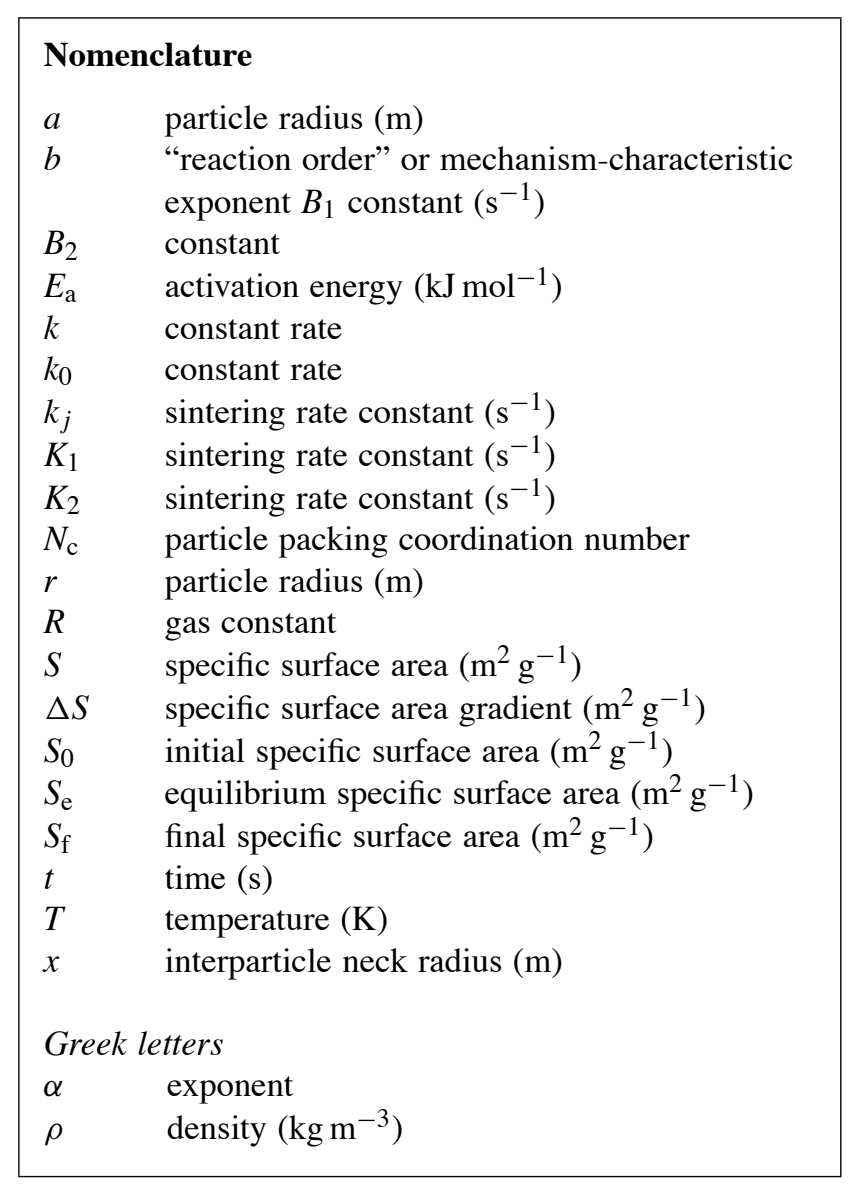

and a detailed experimental study of the change in structural properties caused by sintering. The aim is to understand and compare the structural change, i.e. specific surface area and density of two non-stoichiometric hydroxyapatites during calcination. The two hydroxyapatites have different initial specific surface area and different compositions in terms of their $\mathrm{Ca} / \mathrm{P}$ ratios which are of 1.6004 for the first and 1.7275 for the second. In comparison, the $\mathrm{Ca} / \mathrm{P}$ ratio of stoichiometric is 1.6667 . The results are compared with literature models describing the sintering process by specific surface area reduction.

\subsection{Theoretical approach of the surface reduction phenomenon during sintering}

Structural property changes, although quite complex, can be grouped into two major categories. The first consists of changes which occur as the result of sintering while the second category is associated with chemical reaction and occurs when molar volumes of the solid reactant and the solid product are different. Most models have concentrated upon the first category addressing the reaction sintering problem [13-15].

Sintering is broadly defined as the consolidation on heating of a loose mass of particles to a denser mass. Sintering causes both the specific surface area and the porosity to decrease and the density to increase. The Tammann temperature of the solid (0.4-0.5 of the melting point), is considered to be the temperature below which sintering does not occur to any appreciable extent.

Sintering occurs in three stages shown in Fig. 1. In the initial stage, the areas of contact between adjacent particles form and grow. In the intermediate stage, growing necks merge and the large number of small particles are replaced by a smaller number of large particles. This stage produces interparticle porosity whose surface may be inaccessible both to reactant gas during the reaction and to the nitrogen used to measure the specific surface area. In the final stage of sintering, the pore spaces become broken up with isolated closed pores remaining which shrink in size as densification proceeds [16].

A model of the interparticle neck shape during sintering was proposed [17-22]. Through this model, various geometric parameters have been interrelated precisely. An important result of this approach is that the kinetic dependence for the rate of surface area reduction on the operative sintering mechanism has been established. Thus, the mass transport process can be identified via the kinetics of the specific surface area reduction. The proposed identification technique is applied to a variety of sintering data and discussed in terms of the underlying significance of the model. Several neck-growth kinetic equations have been provided based on the format of Kuczynski's initial derivation. The basic model is amenable to an alternative analysis aimed at extracting a time-dependence for surface area reduction. The neck-growth models generally take form

$\left(\frac{x}{a}\right)^{n}=B t$

where $x / a$ is the ratio of interparticle neck radius to the particle radius, $B$ a constant (includes particle size, temperature, and geometric term), $t$ the sintering time, and $n$ the mechanism-characteristic exponent which is dependent on the mass transport process. In the configuration of Fig. 1, the interparticle neck shape is assumed to be formed by a torus of radius $r$ (Fig. 2).

For small neck sizes such an approximate neck shape has little influence on the result. The significant point of Eq. (1) represents sintering driven by the curvature gradient in the neck region. Thus initial sintering does not result from excess surface energy but rather from the chemical potential gradient produced by the varying mean curvature.

Eq. (1) can be recast to give surface area reduction for the case of a small neck where surface area loss with neckgrowth can be approximated as

$\Delta S=S_{0}-S \approx \pi r^{2}$

where $S$ is the surface area at a neck size of $x$ and $S_{0}$ the initial surface area. For compact of spherical powder, the initial surface area per interparticle contact is given by

$S_{0}=\frac{4 \pi a^{2}}{N_{\mathrm{c}}}$

where $N_{\mathrm{c}}$ is the particle packing coordination number which is related to the green density. 


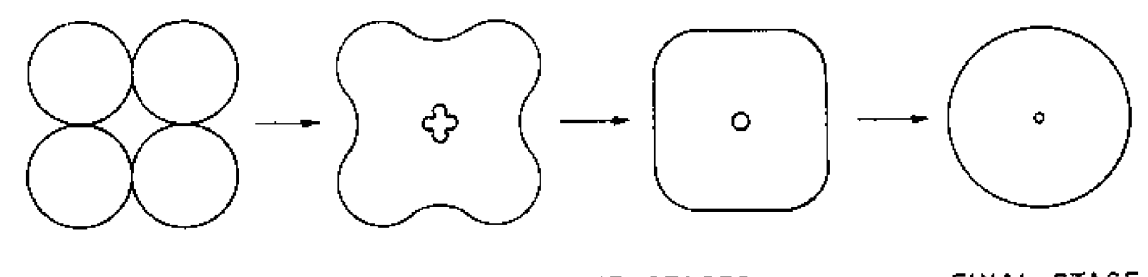

INITIAL STAGE

INTERMEDIATE STAGES

FINAL STAGE
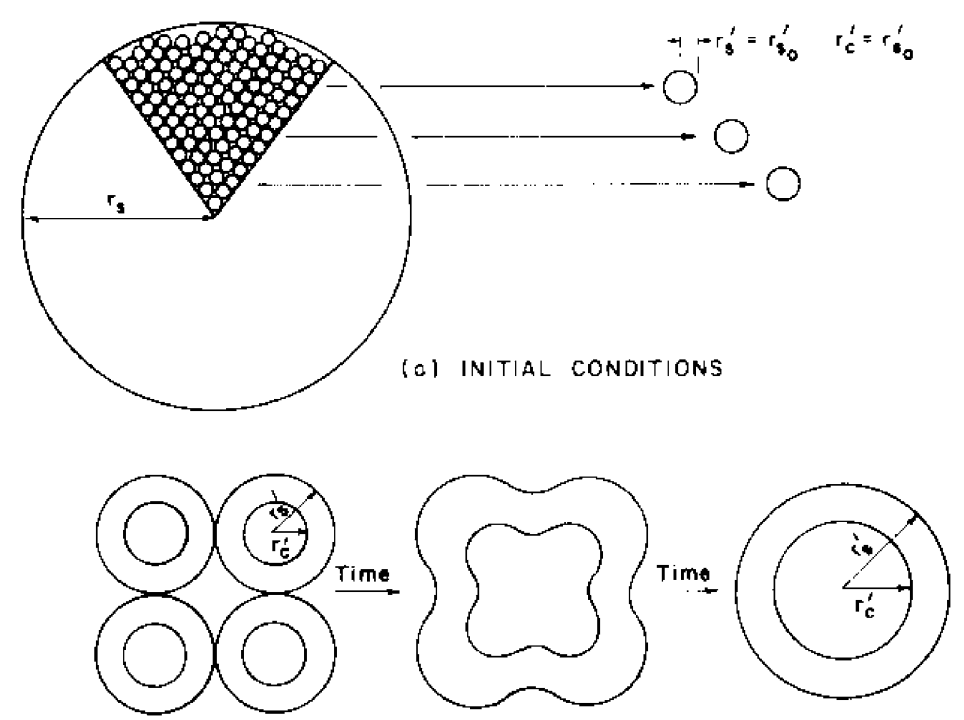

(b) SINTERING

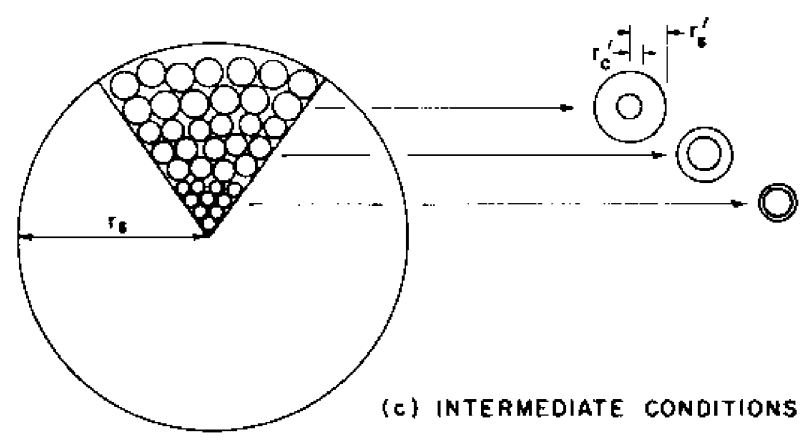

Fig. 1. Sintering phenomenon [13].

Eq. (1) is generalized by the following relationship $[13,17]:$

$\left(\frac{S_{0}-S}{S_{0}}\right)^{\alpha}=K_{1}(T) t$

The exponent $\alpha$ is related to the sintering mechanism through particle coordination for monodispersed spheres $[18,19]$. The values of $\alpha$ have been derived from the accepted time-dependencies of various neck-growth mechanisms.

\subsubsection{Model limitations}

Several results show errors emerging from the assumed functional independence of the surface area reduction on neck size $[13,17]$. Identification of the rate-controlling sin- tering process through the kinetics of specific surface area reduction involves a number of assumptions. For the model used, the particles are assumed to be monodispersed spheres. Large deviations in either particles shape or size distribution produce anomalous effects not accounted for by the model. Because the original calculations were for isolated necks, the point at which neighbouring necks impinge on each other, approximately at $\left(\left(S_{0}-S\right) / S_{0}\right) \cong 0.5$, determines the limit of the model [17].

Shrinkage provides an important check for consistency in applying this approach to sintering studies; bulk and surface transport mechanisms can be distinguished by shrinkage checks. In general, such determinations can result from a few simple density or length measurements during the experiment. 


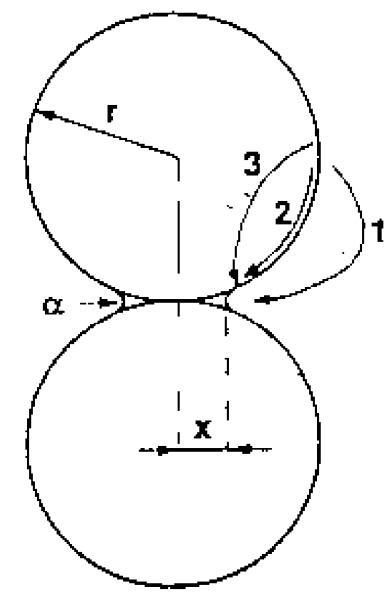

Fig. 2. Interparticle neck shape: (1) diffusion in gas phase; (2) surface diffusion; (3) volume diffusion.

The original surface area $\left(S_{0}\right)$ must be determined accurately. Uncertainties in $S_{0}$ will greatly influence $\Delta S$ and thus, produce variable a values. Optimal analysis by the kinetics of surface area reduction should, therefore, include an accurate measurement of $S_{0}$ followed by multiple surface area measurements over a wide range of times up to $\left(\left(S_{0}-S\right) / S_{0}\right) \cong$ 0.5 . Such an approach minimizes the potential error associated with measuring the slope of a $\log -\log$ data plot. As in most sintering studies, rapid specimen heating and cooling is presumed. However, the simultaneous action of two mechanisms can lead to an improper analysis by using only this technique.

A few studies have examined the effect of sintering on solid surface area. Nicholson described the relationship between surface area, time, and temperature as follows:

$\frac{\mathrm{d} S}{\mathrm{~d} t}=-K_{2}(T)\left(S-S_{\mathrm{f}}\right)$

This relationship was verified with the data of sintering of magnesium oxide and iron oxide. Caillet and Harrisson [13] used this equation to correlate their $\mathrm{ZnO}-\mathrm{ZnS}$ sintering data. The temperature dependence $k(T)$ was expressed by an Arrhenius equation and the equilibrium surface area at any temperature, $S_{\mathrm{f}}$ was determined experimentally.

Nicholson [23] has shown that the specific surface area of a non-reacting, sintering solid varies with time according to the equation:

$\frac{S(t)-S_{\mathrm{e}}}{S_{0}-S_{\mathrm{e}}}=\mathrm{e}^{-k_{j} t}$

Both the sintering rate constant, $k_{j}$ and the equilibrium surface area, $S_{\mathrm{e}}$, are functions of temperature and must be determined experimentally. When and Ishida [24], Ranade and Harrison [25] related specific surface area and grain radius by assuming that all the grain are non-porous spheres having equal radius $r$, defined as follows:

$r=\frac{3}{S \rho}$
German [26] postulated that, at the intermediate stage of sintering the surface area reduction kinetics followed a power law equation

$\frac{\mathrm{d} S}{\mathrm{~d} t}=-B^{\prime}(T) S^{b}$

The functional relationship of $B^{\prime}(T)$ with temperature was not discussed; the exponent $b$ was reported to be between 2.6 and 3.3 for various materials. Schaffler et al. [27] and Caillet and Harrisson [13] also used a power law equation to describe the surface area variation of silica-alumina catalysts in steam at temperatures from 478 to $863^{\circ} \mathrm{C}$. Reported values of the exponent, $b$, ranged from 9.1 at the lower temperature to 3.8 at the higher.

Compared to neck size and shrinkage measurements, surface area offers several advantages as a sintering-process monitor, because the surface area reductions accompany all sintering mechanisms, and it is an easily measurable quantity [26]. Also, the surface area is affected very little by the rearrangement events of the initial stage of sintering. Such measurements average many neck-growth events without tedious neck size measurements. Surface area as a sintering parameter is most appropriate to fine particles, a size region where it is difficult to measure neck diameter.

The basis for using surface area monitoring in the intermediate stage is the statistical sintering model of Kuczynski [28]. In this model the pore-elimination and grain growth processes are coupled to explain the intermediate and final stages of sintering (for crystalline materials).

This phenomenon of bonding of the two particles will take place in order to decrease the total surface area, even though the temperature is lower than the melting point (Tamman temperature) [28].

\section{Materials and methods}

\subsection{Synthesis of hydroxyapatite (HAP) powder}

The experiments were carried out with two hydroxyapatites synthesized at room temperature by precipitation in solution [30]. The first one, $\mathrm{HAP}_{\mathrm{TCP}}$, was obtained according to the reaction (9) between calcium chloride $\left(\mathrm{CaCl}_{2} \cdot 2 \mathrm{H}_{2} \mathrm{O}\right.$ from Aldrich, $98 \%$ minimum), and phosphoric acid $\left(\mathrm{H}_{3} \mathrm{PO}_{4}\right.$ from Prolabo, $85 \%$ minimum). The $\mathrm{pH}$ was adjusted with caustic soda solution. The temperature of the solution was maintained at $298 \mathrm{~K}$. The second hydroxyapatite, $\mathrm{HAP}_{\mathrm{CaO}}$, was prepared by mixing calcium nitrate $\left(\mathrm{Ca}\left(\mathrm{NO}_{3}\right)_{2}\right.$ from Norskhydro $)$ and ammonium phosphate $\left(\left(\mathrm{NH}_{4}\right)_{2} \mathrm{HPO}_{4}\right.$ from Norskhydro) at $100{ }^{\circ} \mathrm{C}$ and the $\mathrm{pH}$ was adjusted to 7-8 with a $20 \%$ ammonia solution according to reaction (10):

$$
\begin{aligned}
& 10 \mathrm{CaCl}_{2}+6 \mathrm{H}_{3} \mathrm{PO}_{4}+20 \mathrm{NaOH} \\
& \quad \rightarrow \mathrm{Ca}_{10}\left(\mathrm{PO}_{4}\right)_{6}(\mathrm{OH})_{2}+20 \mathrm{NaCl}+18 \mathrm{H}_{2} \mathrm{O}
\end{aligned}
$$




$$
\begin{aligned}
& 10 \mathrm{Ca}\left(\mathrm{NO}_{3}\right)_{2}+6\left(\mathrm{NH}_{4}\right)_{2} \mathrm{HPO}_{4}+8 \mathrm{NH}_{4} \mathrm{OH} \\
& \rightarrow \mathrm{Ca}_{10}\left(\mathrm{PO}_{4}\right)_{6}(\mathrm{OH})_{2}+20 \mathrm{NH}_{4} \mathrm{NO}_{3}+6 \mathrm{H}_{2} \mathrm{O}
\end{aligned}
$$

\subsection{Characterisation of materials}

The structure and the composition of the dried particles was identified and quantified by X-ray powder diffractometry (Siemens D5000). XRD measurements were carried out with $\mathrm{Cu} \mathrm{K} \alpha$ radiation generated at $40 \mathrm{kV}$ and $40 \mathrm{~mA}$, in the $3^{\circ}<2 \theta<60^{\circ}$ range at a scan speed of $2{ }^{\circ} \mathrm{Cmin}^{-1}$. The phases present were determined by comparing the patterns with JCPDS standards.

Calcium and phosphorus contents in the obtained solids were determined using atomic absorption spectrometry (Varian spectrAA-400 plus).

The specific surface area of the particles was determined by nitrogen adsorption using a BET method (Micromeretics Gemini Vacprep 061). The value obtained for the dried particles was $28 \mathrm{~m}^{2} \mathrm{~g}^{-1}$ for $\mathrm{HAP}_{\mathrm{TCP}}$ and $104 \mathrm{~m}^{2} \mathrm{~g}^{-1}$ for $\mathrm{HAP}_{\mathrm{CaO}}$.

The bulk density of the powder was measured by helium pycnometry (Micromeritics, Accupyc 1330) and the results obtained are: $d_{\mathrm{HAP}_{\mathrm{TCP}}}=3.1 \mathrm{~g} \mathrm{~cm}^{-3}$, and $d_{\mathrm{HAP}_{\mathrm{CaO}}}=$ $2.79 \mathrm{~g} \mathrm{~cm}^{-3}$.

The particle size distribution of the powder was determined with a Malvern laser mastersizer Hydro 2000. The particles were placed in an ethanol suspension shaken by ultrasound. The mean sizes of $11 \mu \mathrm{m}$ for $\mathrm{HAP}_{\mathrm{TCP}}$ and of $18 \mu \mathrm{m}$ for $\mathrm{HAP}_{\mathrm{CaO}}$ were obtained.

Thermogravimetric and differential thermal analysis (TGTDA) was executed under the following conditions: $30 \mathrm{mg}$ of samples, platinum crucible, an air flow of $100 \mathrm{~cm}^{3} \mathrm{~min}^{-1}$, and heating rate of $10^{\circ} \mathrm{C} \mathrm{min}^{-1}$ from 25 to $1200{ }^{\circ} \mathrm{C}$ using the thermobalance (Seteram TG 92).

\subsection{Sintering procedure}

The shrinkage of particles was followed by thermomechanical analyser (Setaram Setsys 16/20) with $5 \mathrm{~g}$ constant load on the powder sample. Thermal shrinkage was defined as $\Delta L / L_{0}$, where $L_{0}$ is the diameter or thickness of the green specimen. The relative density of sintered hydroxyapatite was expressed using the bulk and theoretical densities $\left(d_{\mathrm{HAP}_{\mathrm{TCP}}}=3.1 \mathrm{~g} \mathrm{~cm}^{-3}\right.$, and $\left.d_{\mathrm{HAP}_{\mathrm{CaO}}}=2.79 \mathrm{~g} \mathrm{~cm}^{-3}\right)$. Two types of experiments were carried out: for the first, a constant heating of $10^{\circ} \mathrm{C} \mathrm{min}^{-1}$ from 30 to $1200{ }^{\circ} \mathrm{C}$ to determine the sintering temperature of the powders and the second, a heating rate of $10{ }^{\circ} \mathrm{C} \mathrm{min}^{-1}$ followed by a plateau of $5 \mathrm{~h}$ at the isotherm temperature.

In parallel, calcination experiments were carried out on a 21 furnace. The heating program was as follows: heating rate of $10^{\circ} \mathrm{C} \mathrm{min}-1$ from $30^{\circ} \mathrm{C}$ to the chosen isotherm temperature and the isothermal stages varying from 0 to $120 \mathrm{~min}$. The samples were placed in alumina crucible and heated at different rates up to the selected temperature under flowing air, then held for the same time and cooled at the same rate with a maximum heating temperature of $1600^{\circ} \mathrm{C}$.

\section{Results and discussion}

\subsection{Effect of thermal conditions on the structure of amorphous calcium phosphate (ACP)}

The XDR patterns of Fig. 3 show the presence of an amorphous phase at temperatures below $500{ }^{\circ} \mathrm{C}$. The sample

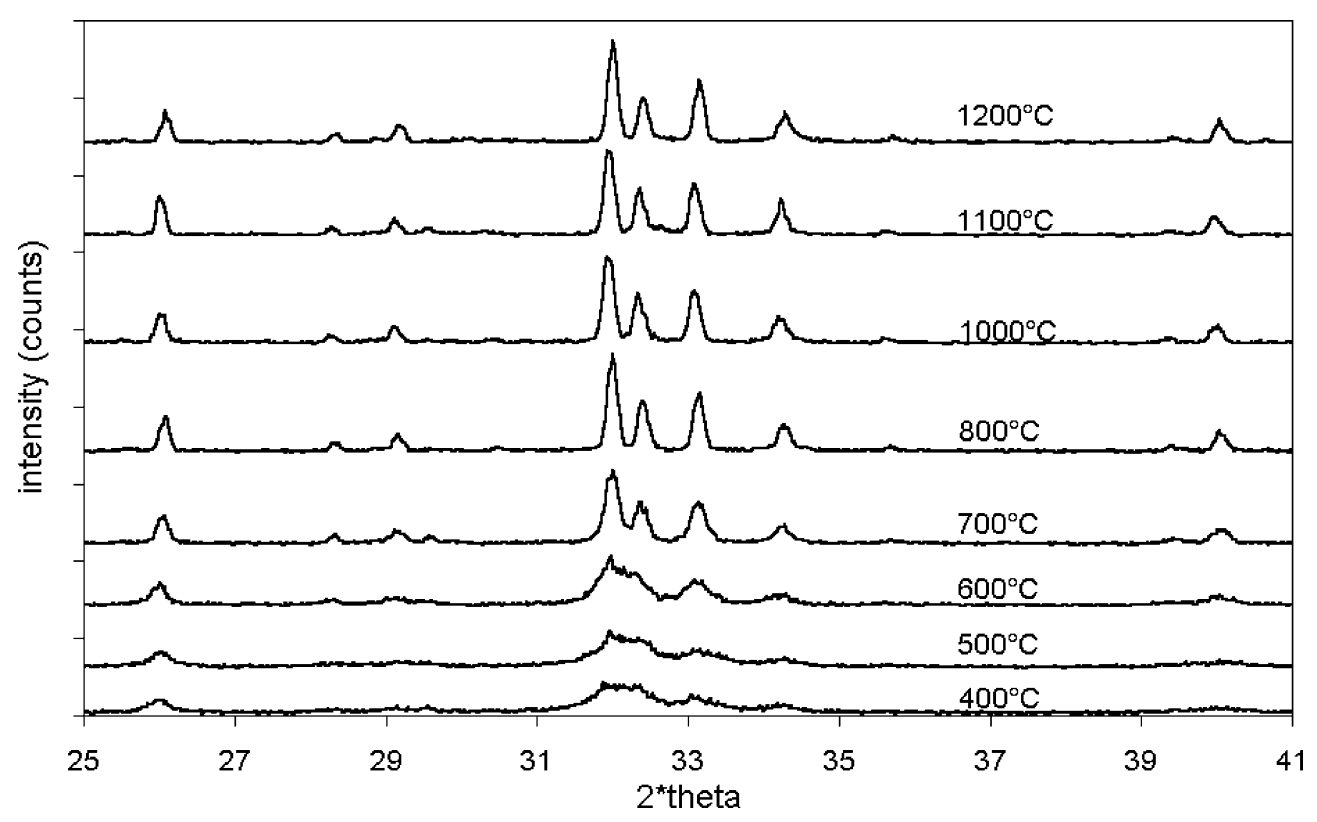

Fig. 3. XRD pattern of $\mathrm{HAP}_{\mathrm{CaO}}$ vs. the calcination temperature. 
heated at temperatures greater than $600^{\circ} \mathrm{C}$ exhibited broad peaks on a apatite phase. When the temperature was increased, the apatitic peaks became sharper, because of crystal growth. Each pattern has hydroxyapatite as the major phase component. However, trace and significant amounts of other phases were detected. These phases are essentially composed by intermediate calcium phosphates between ACP and HAP.

The XRD references were obtained according the AFNOR standard [31]. Then, the two hydroxyapatites were calcined during $15 \mathrm{~h}$ at $1000{ }^{\circ} \mathrm{C}$. The calcination allows the crystallization of the particles by comparison with the dried particles as it is shown in Fig. 4a for $\mathrm{HAP}_{\mathrm{TCP}}$ and in Fig. 4b for $\mathrm{HAP}_{\mathrm{CaO}}$. The evolution of the cell parameters $(a, b, c)$ and the crystallite mean size of HAP particles are not discussed in this paper. Nevertheless, approximately $39 \mathrm{wt} . \%$ of tricalcium phosphate $\left(\mathrm{Ca}_{3}\left(\mathrm{PO}_{4}\right)_{2}\right)$ was present in
$\mathrm{HAP}_{\mathrm{TCP}}$ and about 2 wt. $\%$ of $\mathrm{CaO}$ was detected in $\mathrm{HAP}_{\mathrm{CaO}}$. These XRD patterns of the calcined particles help to conclude that $\mathrm{HAP}_{\mathrm{TCP}}$ is a $\mathrm{ACP}$ with a $\mathrm{Ca} / \mathrm{P}$ ratio of 1.6004 which becomes a mixture of hydroxyapatite and tricalcium phosphate (TCP) at high temperature and $\mathrm{HAP}_{\mathrm{CaO}}$ is a ACP with a $\mathrm{Ca} / \mathrm{P}$ ratio of 1.7275 which becomes a mixture of lime $(\mathrm{CaO})$ and hydroxyapatite at high temperature. Since the $\mathrm{Ca} / \mathrm{P}$ ratio of stoechiometric hydroxyapatite is 1.6667 , the first, $\mathrm{HAP}_{\mathrm{TCP}}$, is a calcium deficient hydroxyapatite and the second, $\mathrm{HAP}_{\mathrm{CaO}}$, is an hydroxyapatite with a calcium excess.

\subsection{Sintering and shrinkage of hydroxyapatite matrix}

The linear shrinkage and relative density of ACP and derived HAP are plotted in Fig. 5. The two hydroxyapatite powders have been studied by the thermomechanical
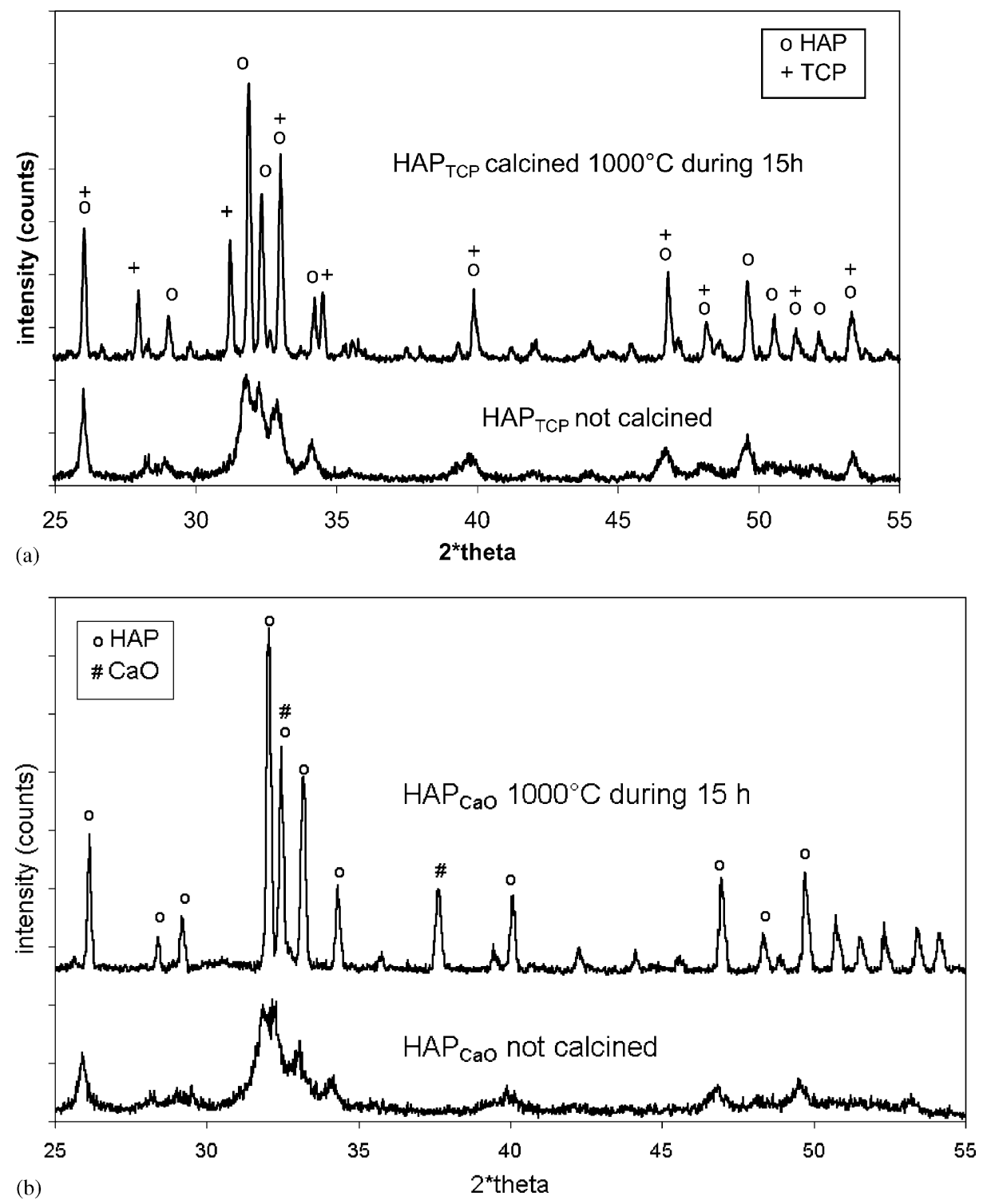

Fig. 4. (a) XRD pattern of (a) $\mathrm{HAP}_{\mathrm{TCP}}$ and (b) $\mathrm{HAP}_{\mathrm{CaO}}$ not calcined and calcined at $1000^{\circ} \mathrm{C}$ during $15 \mathrm{~h}$. 

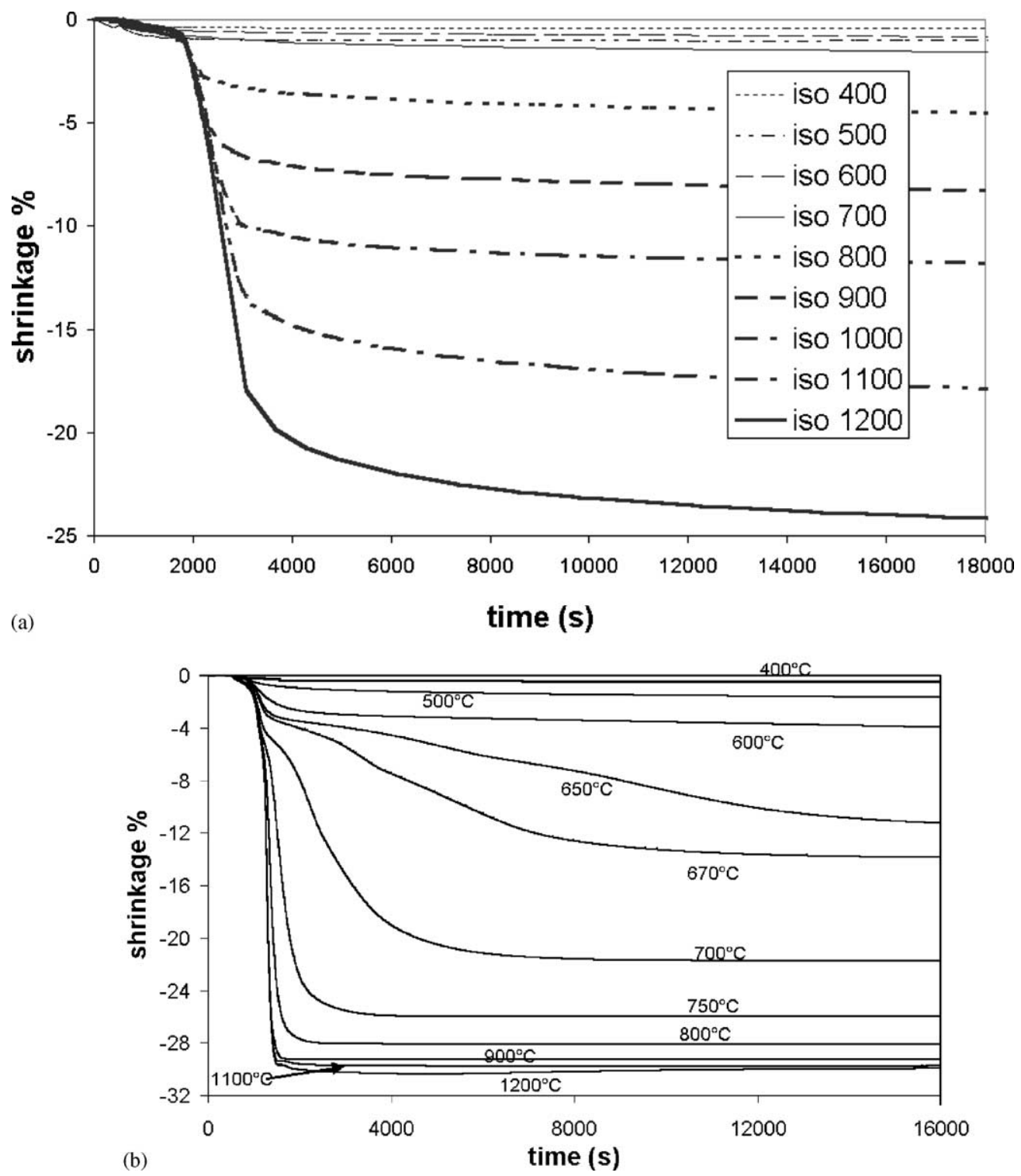

Fig. 5. Dilatometric curves of (a) $\mathrm{HAP}_{\mathrm{TCP}}$ and (b) $\mathrm{HAP}_{\mathrm{CaO}}$ during isothermal runs.

analyzer in dynamic mode and in isotherm mode from 100 to $1200{ }^{\circ} \mathrm{C}$. The results presented in Fig. 5a show the shrinkage of $\mathrm{HAP}_{\mathrm{TCP}}$ which begins at $750{ }^{\circ} \mathrm{C}$ stops at $1200^{\circ} \mathrm{C}$. This sintering temperature is similar to that published in the literature for stoichiometric hydroxyapatite [32,33]. In isotherm curves of Figs. 5 and 6 no significant shrinkage was measured at the temperature less than $700{ }^{\circ} \mathrm{C}$. For the $\mathrm{HAP}_{\mathrm{TCP}}$ the final shrinkage percentage is $20 \%$. For $\mathrm{HAP}_{\mathrm{CaO}}$ (Fig. 5b), the shrinkage begins at $600{ }^{\circ} \mathrm{C}$, this temperature corresponds to the decomposition of lime $\mathrm{Ca}(\mathrm{OH})_{2}$ to $\mathrm{CaO}$. The reduction of length observed can be explained by the combined effect of shrinkage and the evaporation of water. At $900{ }^{\circ} \mathrm{C}$, the sample height does not change any more: in this case, the final shrinkage is $30 \%$.

The evolution observed occurs simultaneously with the reduction of the specific surface area of the particle. In fact, a significant surface reduction is observed both for $\mathrm{HAP}_{\mathrm{TCP}}$ and $\mathrm{HAP}_{\mathrm{CaO}}$.

For $\mathrm{HAP}_{\mathrm{TCP}}$, below $500^{\circ} \mathrm{C}$, the shrinkage is lower than $1 \%$ (Fig. 6). The specific surface area (Fig. 7) is constant and equal to that of the initial particles $\left(28 \mathrm{~m}^{2} \mathrm{~g}^{-1}\right)$. In this domain, the structure of the particles does not change significantly.

For the temperatures above $650^{\circ} \mathrm{C}$, the shrinkage percentage increases linearly with the temperature like it is shown in Fig. 6. At $1000^{\circ} \mathrm{C}$, we can notice a break in the line that corresponds to a mechanism change. Because the slope of the line is more important, it may represent the beginning of a new reaction. This result is confirmed by the thermogravimetric curve of Fig. 8a in which we can see that the weight loss percentage increases significantly above $1000{ }^{\circ} \mathrm{C}$. The initial specific surface area of $28 \mathrm{~m}^{2} \mathrm{~g}^{-1}$ is 


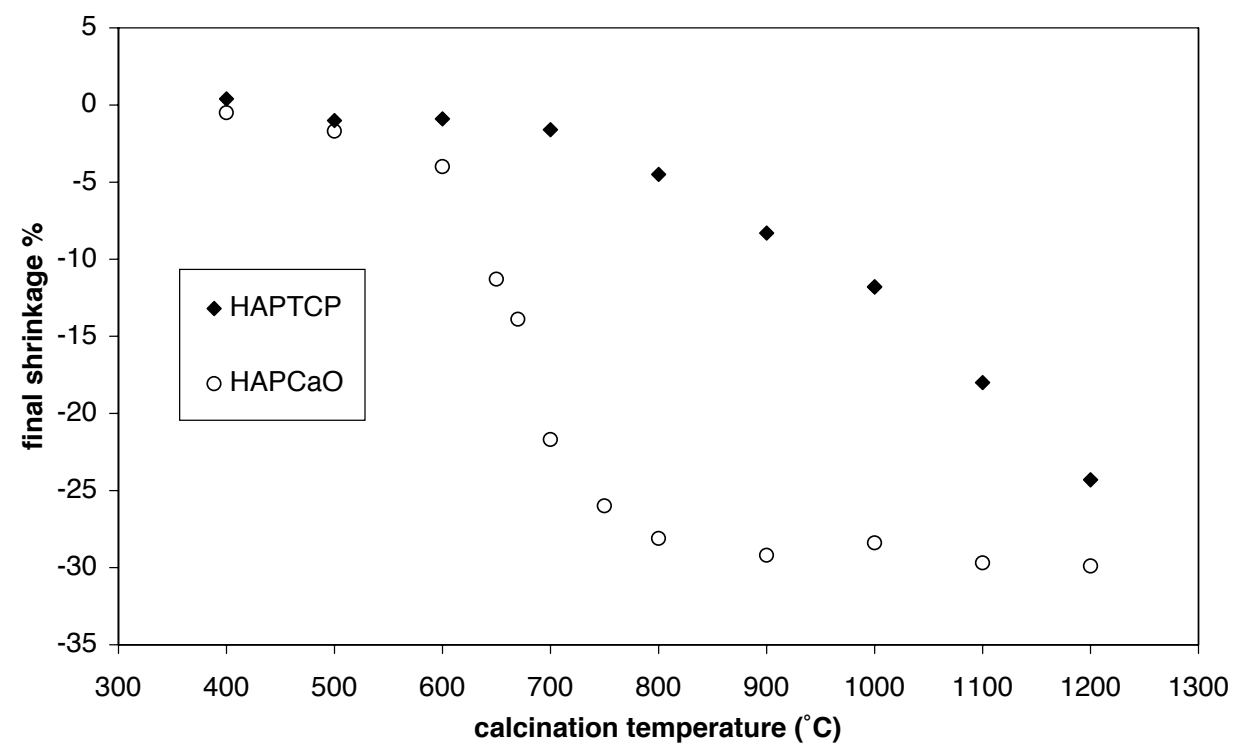

Fig. 6. Final shrinkage (\%) vs. the calcination temperature.

reduced to $3 \mathrm{~m}^{2} \mathrm{~g}^{-1}$ from 550 to $1000{ }^{\circ} \mathrm{C}$. Above $1000{ }^{\circ} \mathrm{C}$ no significant specific surface area reduction is observed.

For $\mathrm{HAP}_{\mathrm{CaO}}$, the shrinkage is effective between 500 and $900{ }^{\circ} \mathrm{C}$. Under $500{ }^{\circ} \mathrm{C}$, the shrinkage percentage (Fig. 5a) is less than $1 \%$ and the specific surface area is constant (Fig. 7). Above $900{ }^{\circ} \mathrm{C}$, all the dilatometric curves are superposed (Fig. 5b) and the specific surface area is constant showing that the structure does not change any more.

Between 500 and $900{ }^{\circ} \mathrm{C}$, the shrinkage percentage increases linearly with the temperature like it is shown in Fig. 6. This shrinkage corresponds to the decreases of the specific surface area (Fig. 7) from 104 to 2 or $3 \mathrm{~m}^{2} \mathrm{~g}^{-1}$. The corresponding processes are the shrinkage and the decomposition of $\mathrm{Ca}(\mathrm{OH})_{2}$, corresponding to the weight loss on Fig. 8 b between 500 and $750{ }^{\circ} \mathrm{C}$.

Fig. 8 gives the evolution of the theoretical density obtained by calculation from the data of the shrinkage and weight loss as a function of temperature obtained by experiments. The experiments were carried out with $20 \mathrm{mg}$ of the powder and the heating program was follows: heating rate of $10{ }^{\circ} \mathrm{C} \mathrm{min}{ }^{-1}$ from 50 to $1200{ }^{\circ} \mathrm{C}$ with two stages of $15 \mathrm{~min}$ at 400 and $900{ }^{\circ} \mathrm{C}$.

The hypothesis made is that the variations of particle dimensions are isotropic and the mass weight remains constant

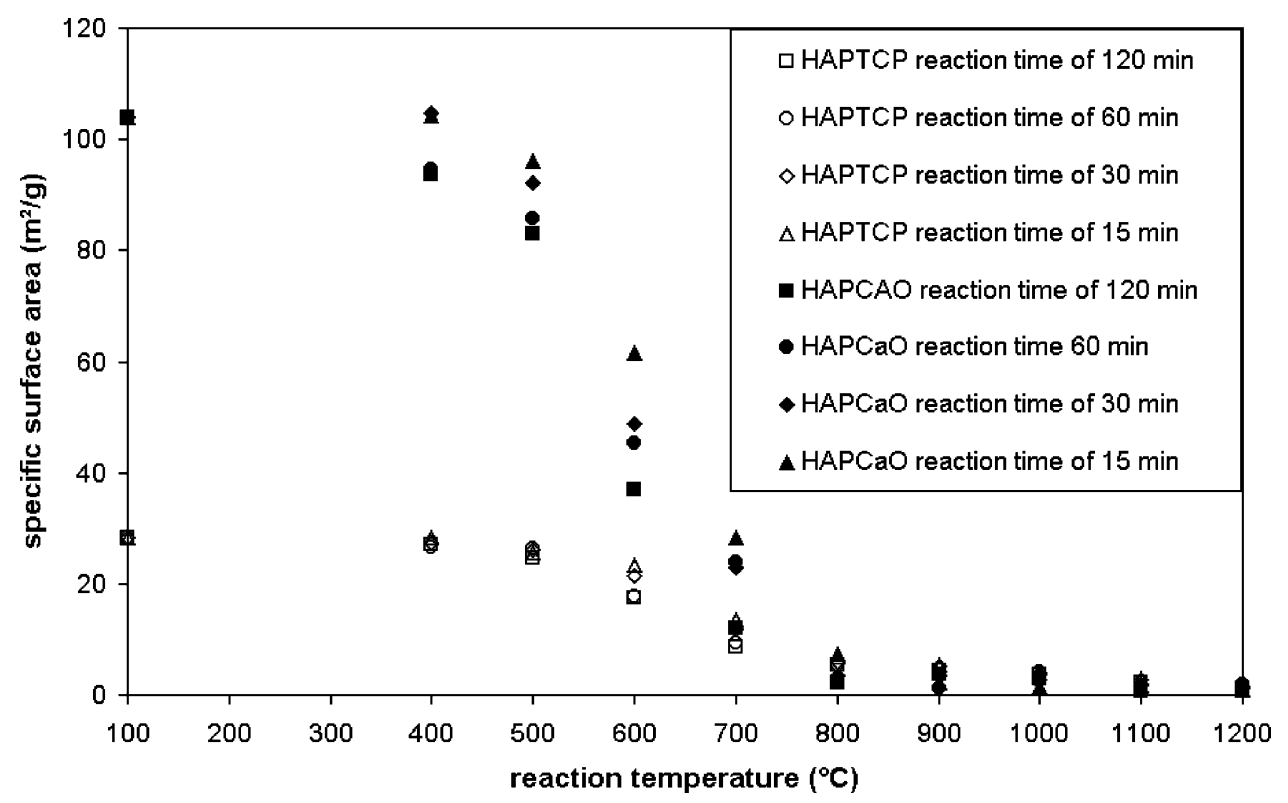

Fig. 7. Specific surface area curves of $\mathrm{HAP}_{\mathrm{TCP}}$ and $\mathrm{HAP}_{\mathrm{CaO}}$ during the isothermal runs. 

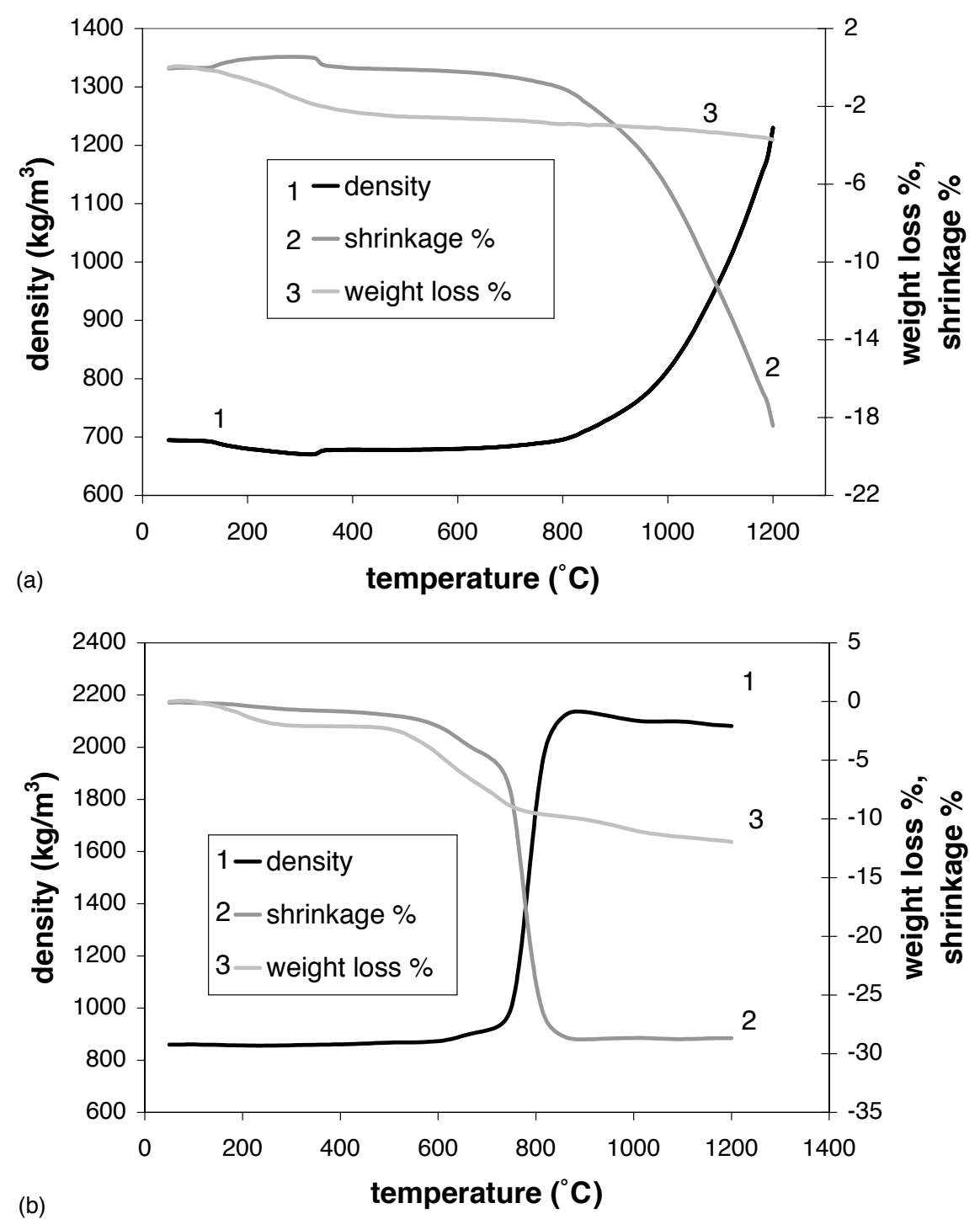

Fig. 8. Shrinkage, density and weight loss (\%) of (a) $\mathrm{HAP}_{\mathrm{TCP}}$ and (b) $\mathrm{HAP}_{\mathrm{CaO}}$.

in the temperature range investigated. So the density is calculated by the following formula:

$\rho=\frac{m_{0}(1-\text { weight loss percentage })}{\pi r h_{0}(1-\text { shrinkage percentage })}$

Fig. $8 \mathrm{a}$ and $\mathrm{b}$ shows that under $500^{\circ} \mathrm{C}$, the density of both $\mathrm{HAP}_{\mathrm{TCP}}$ and $\mathrm{HAP}_{\mathrm{CaO}}$ are constant, but after it increases confirming the sintering.

A curve with an inflexion point at $\sim 1100{ }^{\circ} \mathrm{C}$ was then observed. The shrinkage reached a maximum of $-20 \%$ at $1100^{\circ} \mathrm{C}$, when the HAP structure became unstable. The ACP sample shrank at a considerably lower temperature than the HAP samples. The curves showed a step $(-6.5 \%)$ at $600^{\circ} \mathrm{C}$ that coincided with the crystallization of ACP. At higher temperatures, the curve stabilised to a plateau up to $850^{\circ} \mathrm{C}$. Finally, the relative density increased at $1000{ }^{\circ} \mathrm{C}$ and attained a value of $91.4 \%$ at $1100{ }^{\circ} \mathrm{C}$.

\subsection{Sintering kinetic study}

All samples were analyzed by the method in order to determine the specific surface area as a function of time and temperature for the two hydroxyapatites investigated (Fig. 7). Three models of the literature (Table 1) were used to correlate the experimental data showing the decrease of specific surface area. The principles of these models were related in Section 1 of this paper.

The equations of Table 1 were solved using Matlab software. The required initial condition is the initial specific surface area and the temperature range. The results obtained are compared in Fig. 9a for $\mathrm{HAP}_{\mathrm{TCP}}$ and in Fig. $9 \mathrm{~b}$ for $\mathrm{HAP}_{\mathrm{CaO}}$.

Fig. $9 \mathrm{a}$ and $\mathrm{b}$ shows that the Nicholson equation does not fit the experimental data well for the two hydroxyapatites. The value derived for the $\alpha$ and $b$ exponent parameters were used to chose the best model. Indeed, $y$ values of more than 
Table 1

Specific surface area models used

\begin{tabular}{llll}
\hline German [26] & Nicholson [23] & Schaffler et al. [27] \\
\hline$\left(\frac{S_{0}-S}{S_{0}}\right)^{\alpha}=K_{1}(T) t$ & $(4)$ & $\frac{\mathrm{d} S}{\mathrm{~d} t}=-K_{2}(T)\left(S-S_{\mathrm{f}}\right)$ & $(5)$
\end{tabular}

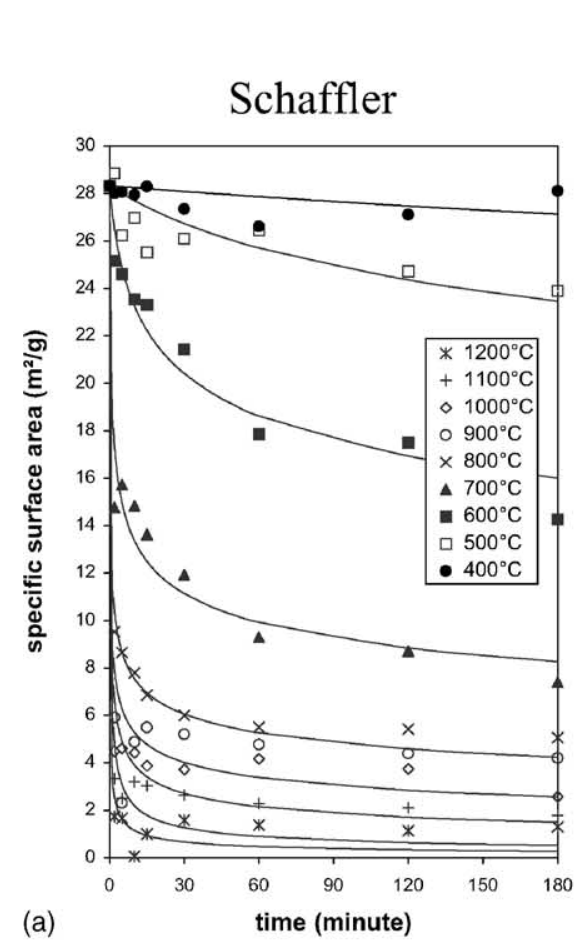

$\mathrm{HAP}_{\mathrm{TCP}}$

Nicholson

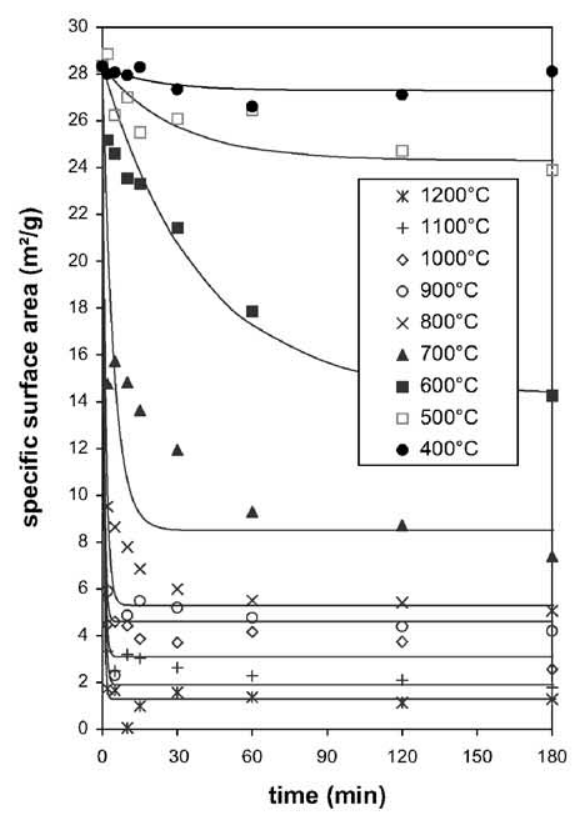

German

$\mathrm{HAP}_{\mathrm{CaO}}$

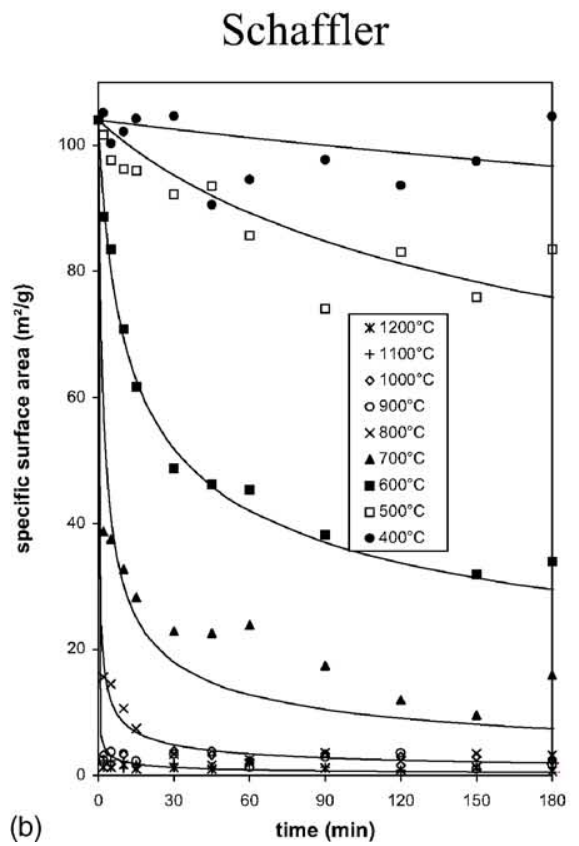

Nicholson
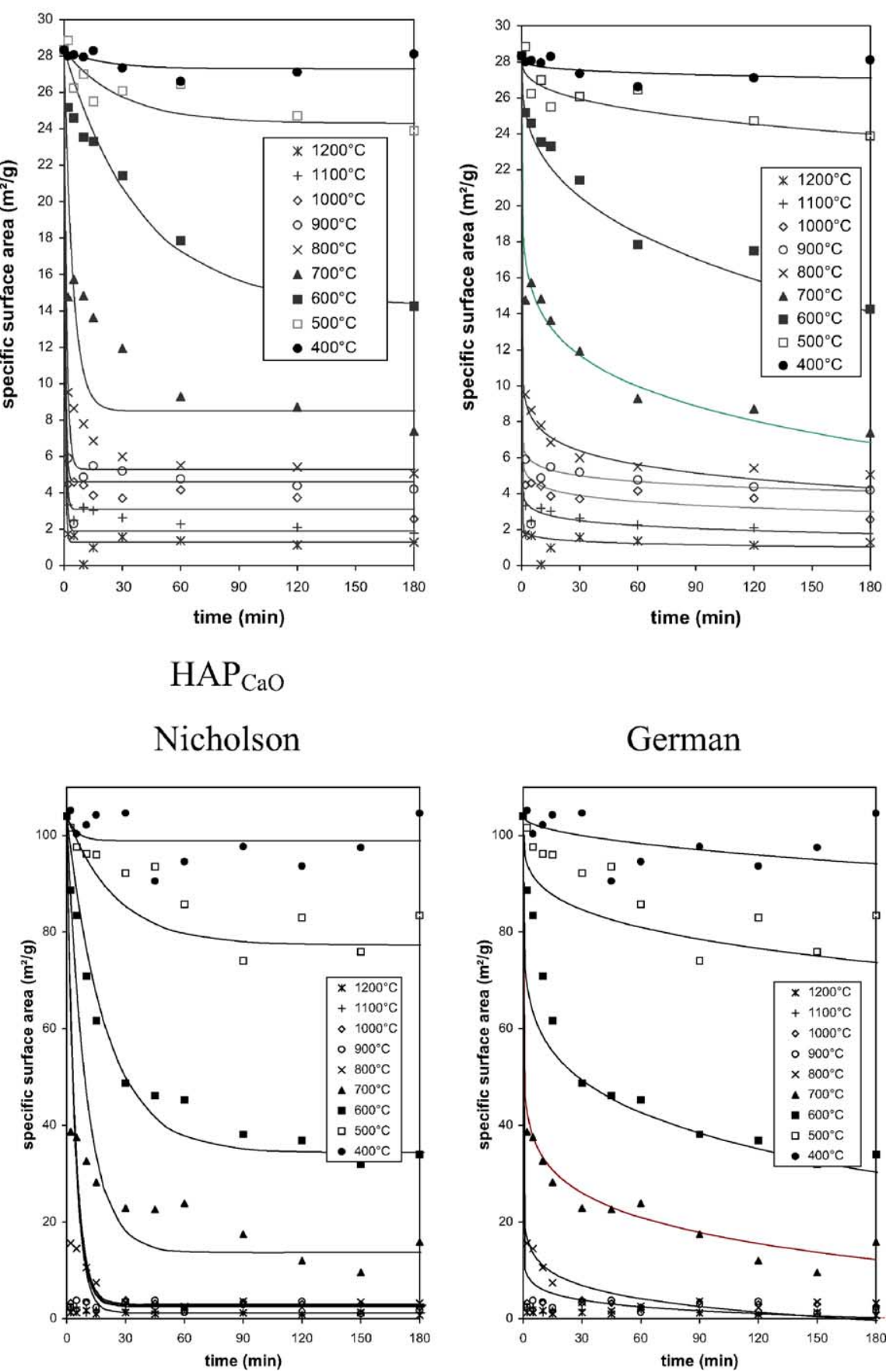

German

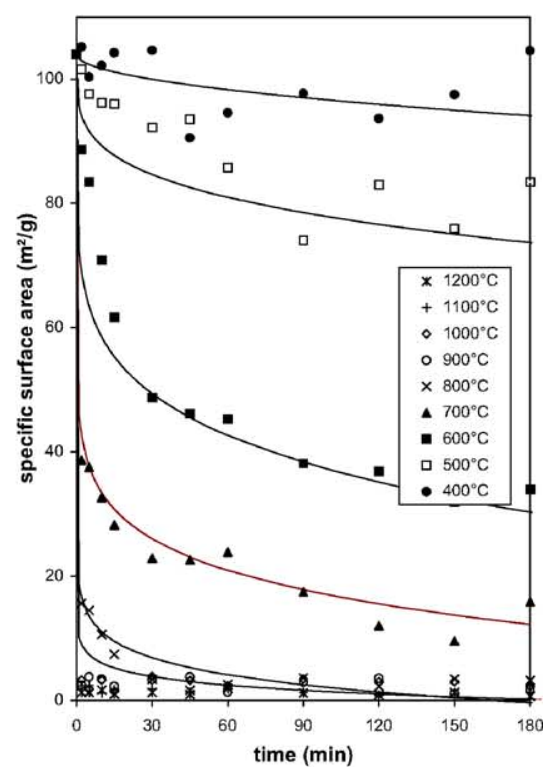

Fig. 9. Modelling of experimental data of surface reduction for (a) $\mathrm{HAP}_{\mathrm{TCP}}$ and (b) $\mathrm{HAP}_{\mathrm{CaO}}$. 
50 were found for the two hydroxyapatites which is not realistic. For the Schaffler model, the value of the constant $b$ of Eq. (8) which vary from 3 to 10 with changing temperature for the two hydroxyapatites are in good agreement with those found in the literature. The value of $b$ decreases regularly from 10 to 3 from 500 to $1200{ }^{\circ} \mathrm{C}$. The changing value of $b$, which may be termed the "order" of the reaction, suggests that the mechanism of surface area reduction which was identified as a diffusion mechanism may be changing with temperature $[13,17,27,29,32]$. The Schaffler model (Eq. (8)) was chosen to fit the specific surface area data. This model appears to have considerable merit in determining the dominant mass transport mechanism during the sintering. The assumption that the surface energy provides the driving force for sintering has led to proposals for kinetic laws represented by Eq. (8). This empirical model is in agreement with the specific surface area changes for many systems over time periods during initial, intermediate and final sintering stages.

In the Schlaffler model, the constant rate $B(T)$ expressed the temperature dependence of the specific surface area. This dependence was determined using the Arrhenius equation indicated by Eq. (12).

$B(T)=k_{0} \mathrm{e}^{-E_{\mathrm{a}} / R T}$

The activation energy $E_{\mathrm{a}}$ of sintering was then deduced (Fig. 10). The values of $385 \mathrm{~kJ} \mathrm{~mol}^{-1}$ for $\mathrm{HAP}_{\mathrm{TCP}}$ and $371 \mathrm{~kJ} \mathrm{~mol}^{-1}$ for $\mathrm{HAP}_{\mathrm{CaO}}$ are in good agreement with the value of $400-500 \mathrm{~kJ} \mathrm{~mol}^{-1}$ reported by Raynaud et al. [33] for stoichiometric hydroxyapatites [34].

\section{Conclusions and perspectives}

The behaviour during the calcination of two non-stoichiometric hydroxyapatites (calcium deficient and calcium excess) were investigated. In both case, a significant decrease of the specific surface area and an increase of the density was observed versus the temperature and the duration of the calcination. The hydroxyapatite begins to shrink near $780{ }^{\circ} \mathrm{C}$ and reaches $97 \%$ theoretical density at $1100{ }^{\circ} \mathrm{C}$. The kinetics of this sintering process was investigated and compared with the results of the literature which takes into account the structural change of the particles on calcination and a good agreement is observed. The changing value of $b$, which may be termed the "order" of the reaction, suggests that the mechanism for loss of surface area which was identified as a diffusion mechanisms may be changing with temperature $[13,17,27,29,32]$. The Schaffler model appears to help understand the dominant mass transport mechanism during sintering. This study provides evidence that the sintering of ACP powder occurs during the calcination. After heating at $600{ }^{\circ} \mathrm{C}$, the ACP particles crystallize to a HAP phase. Thermal crystallization is accompanied by active surface diffusion within the initial particles, which constitutes the driving force for densification. The present research is focussed on

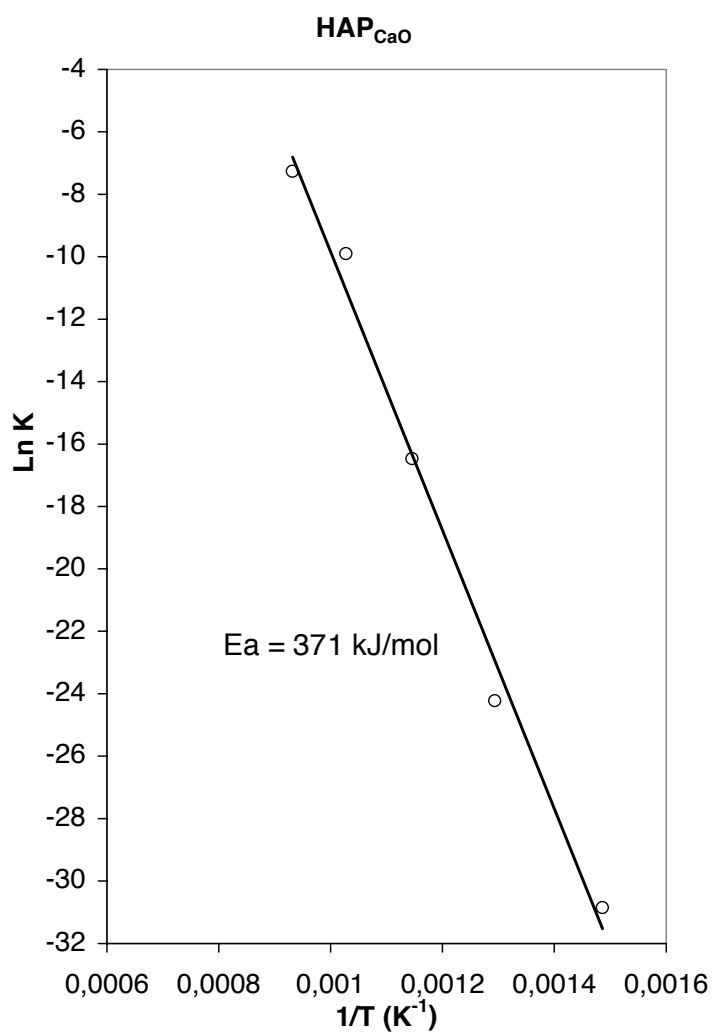

Fig. 10. Activation energy of the sintering phenomenon for $\mathrm{HAP}_{\mathrm{TCP}}$ and $\mathrm{HAP}_{\mathrm{CaO}}$. 
the measurements of the thermal conductivity changes due to the change in porosity of hydroxyapatite particles during the calcination. A grain model which combines the effects of sintering and density changes observed during the calcination of hydroxyapatites powders in fixed bed will be used to help understand the effect of the temperature gradient on the sintering observed from 700 to $1100^{\circ} \mathrm{C}$. The model will also be used to further and further understand the experimental results of the sintering of hydroxyapatite doped with heavy metals.

\section{Acknowledgements}

The authors would like to thank Dr. Didier BernacheAssolant, Dr. Patrick Sharrock and Dr. Eric Champion for stimulating discussion and for their interest in this study.

\section{References}

[1] S. Iretskaya, A. Nzihou, C. Zahraoui, P. Sharrock, Metal leaching from MSW fly ash before and after chemical and thermal treatments, Environ. Prog. 18 (1999) 144-148.

[2] A. Nzihou, P. Sharrock, Calcium phosphate stabilization of fly ash with chloride extraction, Waste Manage. 22 (2002) 235-239.

[3] B.S. Crannell, T.T. Eighmy, J.E. Krzanowski, J.D. Eusden Jr., E.L. Shaw, C.A. Francis, Waste Manage. 20 (2000) 135-148.

[4] Y. Takeuchi, T. Suzuki, H. Arai, A study of equilibrium and mass transfer in processes for removal of heavy-metal ions by hydroxyapatite, J. Chem. Eng. Jpn. 21 (1988) 98-100.

[5] N.C.C. da Rocha, R.C. de Campos, A.M. Rossi, E.L. Moreira, A. doF. Barbosa, G.T. Moure, Cadmium uptake by hydroxyapatite synthesized in different conditions and submitted to thermal treatment, Environ. Sci. Technol. 36 (2002) 1630-1635.

[6] E. Mavropoulos, A.M. Rossi, A.M. Costa, C.A.C. Perez, J.C. Moreira, M. Saldanha, Studies on the mechanisms of lead immobilization by hydroxyapatite, Environ. Sci. Technol. 36 (2002) 16251629.

[7] Q.Y. Ma, S.J. Traina, T.J. Logan, J.A. Ryan, In situ lead immobilisation by apatite, Environ. Sci. Technol. 27 (1993) 18031810 .

[8] T. Suzuki, T. Hatsushika, M. Miyake, Synthetic hydroxyapatites as inorganic cation exchangers. Part 2, J. Chem. Soc., Faraday Trans. I 78 (1982) 3605-3611.

[9] Y. Takeuchi, H. Arai, Removal of coexisting $\mathrm{Pb}^{2+}, \mathrm{Cu}^{2+}$ and $\mathrm{Cd}^{2+}$ ions from water by addition of hydroxyapatite powder, J. Chem. Eng. Jpn. 23 (1990) 75-80.

[10] Q.Y. Ma, S.J. Traina, T.J. Logan, J.A. Ryan, Effect of aqueous Al, $\mathrm{Cd}, \mathrm{Cu}, \mathrm{Fe}(\mathrm{II}), \mathrm{Ni}$ and $\mathrm{Zn}$ on $\mathrm{Pb}$ imobilization by hydroxyapatite, Environ. Sci. Technol. 28 (1994) 1219-1228.

[11] Q.Y. Ma, T.J. Logan, S.J. Traina, J.A. Ryan, Effect of $\mathrm{NO}_{3}{ }^{-}, \mathrm{Cl}^{-}$, $\mathrm{F}^{-}, \mathrm{SO}_{4}{ }^{2-}$ and $\mathrm{CO}_{3}{ }^{2-}$ on $\mathrm{Pb}^{2+}$ immobilization by hydroxyapatite, Environ. Sci. Technol. 28 (1994) 408-418.
[12] S. Bailliez, A. Nzihou, P. Sharrock, Kinetic of sintering of hydroxyapatite powders and adsorption of lead in hydroxyapatite matrices, in: Proceedings of the 6th World Congress of Chemical Engineering, 23-27 September 2001.

[13] D.A. Caillet, D.P. Harrisson, Structural property variations in the MnO-MnS system, Chem. Eng. Sci. 37 (1982) 625-636.

[14] K.K. Kim, J.M. Smith, Diffusion in nickel oxide pellets-effects of sintering and reduction, Am. Inst. Chem. Eng. J. 20 (1974) 670678.

[15] P.V. Ranade, D.P. Harrison, The variable property grain model applied to the zinc oxide-hydrogen sulfide reaction, Chem. Eng. Sci. 36 (1981) 1079-1089.

[16] J. White, in: G.C. Kuczynski (Ed.), Sintering and Related Phenomena, Gordon \& Breach, New York, 1967, p. 245.

[17] R.M. German, Z.A. Munir, Surface area reduction during isothermal sintering, J. Am. Ceram. Soc. 59 (1976) 379-383.

[18] R.M. German, Z.A. Munir, Sintering and catalysis, in: G.C. Kuczynski (Ed.), Materials Sciences Research, vol. 10, Plenum Press, New York, 1975, pp. 249-257.

[19] R.M. German, Z.A. Munir, Sintering and catalysis, in: G.C. Kuczynski (Ed.), Materials Sciences Research, vol 10, Plenum Press, New York, 1975, pp. 259-268.

[20] R.M. German, Z.A. Munir, Identification of the initial stage sintering mechanism using aligned wires, J. Mater. Sci. 11 (1976) 7177.

[21] G.C. Kuzynski, Self-diffusion in sintering of metallic particles, Trans. AIME 185 (1949) 169-178.

[22] D. Gidaspow, in: N. Li (Ed.), Recent Developments in Separation Science, Chemical Rubber Co., Cleveland, 1972, p. 59.

[23] D. Nicholson, Variation of surface area during the thermal decomposition of solids, Trans. Faraday Soc. 61 (1965) 990998.

[24] C.Y. When, M. Ishida, Environ. Sci. Technol. 7 (1973) 703.

[25] P.V. Ranade, D.P. Harrison, The grain model applied to porous solids with varying structural properties, Chem. Eng. Sci. 34 (1979) 427432 .

[26] R.M. German, Surface area reduction kinetics during intermediate stage sintering, J. Am. Ceram. Soc. 61 (1978) 272-274.

[27] W.G. Schaffler, C.Z. Morgan, J.N. Wilson, Aging of silica-alumina cracking catalyst. I. Kinetics of structural changes by heat and steam, J. Phys. Chem. 61 (1957) 714-722.

[28] G.C. Kuczynski, The mechanism of densification during sintering of metallic particles, Acta Metall. 4 (1956) 58-61.

[29] G.C. Kuczynski, Self-diffusion in sintering of metallic particles, Met. Trans. (1949) 169-178.

[30] A. Nzihou, S. Bailliez, Mechanisms of sintering of macroporous hydroxyapatite adsorbents, High Temp. Mater. Proc. 21 (5) (2002) 281-295.

[31] AFNOR NF S 94-066 (1998).

[32] P. Layrolle, A. Ito, T. Tateishi, Sol-gel synthesis of amorphous phosphate and sintering into microporous hydroxyapatite bioceramics, J. Am. Ceram. Soc. 81 (1998) 1421-1428.

[33] S. Raynaud, E. Champion, D. Bernache-Assollant, Calcium phosphate apatites with variable $\mathrm{Ca} / \mathrm{P}$ atomic ratio. II. Calcination and sintering, Biomaterials 23 (2002) 1073-1080.

[34] A. Ababou, Etude experimentale et théorique du préfrittage et du frittage de l'hydroxyapatite $\mathrm{Ca}_{10}\left(\mathrm{PO}_{4}\right)_{6}(\mathrm{OH})_{2}$, Dissertation thesis, Université de Limoges, France, June 1994. 